\title{
Exploring current and potential roles of Australian community pharmacists in gout management: a qualitative study
}

\author{
Allyce B. Counsell ${ }^{1,2}$, Amy D. Nguyen ${ }^{1,3,4^{*}}$ (D), Melissa T. Baysari ${ }^{1,4}$, Diluk R. W. Kannangara ${ }^{1,2}$,
} Andrew J. McLachlan ${ }^{5,6}$ and Richard O. Day ${ }^{1,2,3}$

\begin{abstract}
Background: Gout is an increasingly prevalent form of inflammatory arthritis. Although effective treatments for gout exist, current management is suboptimal due to low medication adherence rates and treatments that are non-concordant with guidelines. Medications are the mainstay and most effective form of gout management. Thus, there is potential for community pharmacists to play an important primary health care role in gout management, however their current role and their potential to improve management of gout treatment is currently unclear. The purpose of the study is to explore the views of Australian pharmacists on their roles in gout management and to identify factors influencing their involvement in gout management.

Methods: A convenience sample of community pharmacists were invited to participate using a snowballing recruitment strategy. Semi-structured, face-to-face interviews were conducted with 15 pharmacists of varying age, gender and pharmacy experience. Interviews focused on pharmacists' experiences of managing gout, interactions with people living with gout and their perceived roles and responsibilities in gout management. Interviews were transcribed verbatim and independently analysed by two reviewers to identify themes.

Results: The main role of pharmacists reported in gout management was providing patient education. The greatest facilitator to pharmacists involvement in gout management was identified to be pharmacists' good understanding of gout and its management. Barriers to pharmacists involvement were identified to be difficulties in monitoring adherence to gout medications, low priority given to gout in the pharmacy compared to other chronic health conditions, and lack of specific training and/or continuing education in gout prevention and management.

Conclusions: Pharmacists can expand their primary health care role in gout management, particularly in the area of ongoing provision of education to people living with gout and in monitoring medication adherence in patients. However, a number of barriers need to be overcome including difficulties in monitoring patient adherence to medications, ensuring a higher priority is given to chronic gout management and providing continuing training to community pharmacists about gout. Implications for pharmacist practice include initiating conversations about medication adherence and education when dispensing medications and undertaking continuing education in gout.
\end{abstract}

Keywords: Gout, Management, Pharmacist, Community pharmacists, Role, Medication adherence, Education

\footnotetext{
* Correspondence: amy.nguyen@mq.edu.au

'Department of Clinical Pharmacology \& Toxicology, St Vincent's Hospital,

Sydney, NSW, Australia

${ }^{3}$ St Vincent's Clinical School, St Vincent's Hospital, University of New South

Wales, Sydney, NSW, Australia

Full list of author information is available at the end of the article
}

(c) The Author(s). 2018 Open Access This article is distributed under the terms of the Creative Commons Attribution 4.0 International License (http://creativecommons.org/licenses/by/4.0/), which permits unrestricted use, distribution, and reproduction in any medium, provided you give appropriate credit to the original author(s) and the source, provide a link to the Creative Commons license, and indicate if changes were made. The Creative Commons Public Domain Dedication waiver (http://creativecommons.org/publicdomain/zero/1.0/) applies to the data made available in this article, unless otherwise stated. 


\section{Background}

Gout is an extremely painful form of inflammatory arthritis characterised by high concentrations of uric acid (UA) in the blood and formation of monosodium-urate crystals within joints resulting in acute inflammation [1]. If left untreated, recurrent gout attacks can result in irreversible joint damage including cartilage loss and bone erosion [1]. Hyperuricaemia (serum UA concentrations > $0.42 \mathrm{mmol} / \mathrm{L}$ (7 $\mathrm{mg} / \mathrm{dL})$ ) is the major risk factor for gout; the higher the UA, the greater the risk [2].

The incidence and prevalence of gout is increasing worldwide [3-5]. For example, recent reviews of Australian data suggested that the prevalence of gout has progressively increased with one study demonstrating it was $0.2 \%$ in 1968 [6], and an updated study reporting gout prevalence as $1.5 \%$ in 2013 [7]. In part, this can be attributed to the ageing population, as the prevalence of gout increases with age [7]. A number of international guidelines have outlined management strategies for gout, incorporating both pharmacological and non-pharmacological aspects [8-12]. Urate-lowering therapies (ULTs), e.g. allopurinol, are the main pharmacological treatments against gout and are typically required life-long to maintain lowered serum UA and reduce the risk of acute attacks [12]. Non-pharmacological interventions include lifestyle advice tailored to maintaining a healthy body weight and avoidance of excessive dietary purine content in food and beverages such as beer and selected seafood. Additionally, consumer education at the time of gout diagnosis is recommended [12].

Despite a good understanding of gout and the availability of effective treatments, current management of gout remains suboptimal [13]. In Australia, the majority of people living with gout are managed by their general practitioner (GP), who typically prescribe medications for gout management and provide some education about gout, diet and lifestyle [14]. However, despite GPs involvement in gout management, some people with gout do not receive optimal treatments concordant with guideline-based care [7, 14, 15]. Similarly, some people living with gout demonstrate suboptimal behaviour in their own gout management [16].

People living with gout have one of the lowest medication adherence rates for any chronic health condition, with one study reporting medication adherence rates of only $35 \%$ after 1 year $[17,18]$. A contributing factor is thought to be the lack of patient understanding of gout and its optimal management [14, 19]. Unsurprisingly, providing comprehensive education to people living with gout has led to improved clinical outcomes. In an observational study, detailed education and close follow-up in people with gout by a research nurse contributed to beneficial outcomes (92\% of participants achieved UA concentrations $\leq 0.36 \mathrm{mmol} / \mathrm{L}$
(6 mg/dL) in 12 months and 65\% reported fewer acute gout attacks than the previous year) [20].

In Australia, community pharmacy is an integral component of the healthcare system by providing timely access to medicines and services that promote quality use of medicines. The role of community pharmacists involves dispensing of medications, provision of education about medications, identification of medication-related issues, medication reviews, and the provision of screening and preventive health care services for patients with chronic health conditions, such as diabetes screening and blood pressure monitoring [21, 22]. Australian pharmacists are currently unable to prescribe 'prescription only' medications, renew or change prescriptions (without authorization of a prescriber), order laboratory tests or easily access patients' medical records. Increasingly, community pharmacists and GPs work more closely in managing people with chronic health conditions, although this has not always been the case [21, 23].

Community pharmacists could potentially improve primary health care management of gout, particularly by enhancing patient adherence to pharmacotherapy for gout. Studies have shown that pharmacists can improve medication adherence rates and therapeutic outcomes, as demonstrated in a number of chronic health conditions, such as diabetes $[24,25]$. Studies from the United Kingdom demonstrated that two simple follow-up consultations with pharmacists providing support for patients with chronic illnesses for problems or concerns regarding their treatment, significantly improved medication adherence $[24,26]$. In a United States study in people living with gout, $35 \%$ of individuals receiving an intervention from a clinical pharmacist achieved UA concentrations $\leq 0.36 \mathrm{mmol} / \mathrm{L}(6 \mathrm{mg} / \mathrm{dL})$, compared to $13 \%$ of patients receiving usual care by a primary care physician after 26 weeks [27]. This specific intervention involved provision of written education material, ongoing support and adjustment of gout medications by clinical pharmacists [27]. Although resource intensive, this demonstrates the potential benefits that pharmacists can have on gout management.

No research to date has specifically investigated the current role of pharmacists in relation to the management of gout. The aim of this study was to explore the current role of Australian community pharmacists in gout management and to identify any perceived facilitators or barriers to community pharmacists in managing, monitoring and treating people living with gout.

\section{Methods}

\section{Recruitment}

A convenience sampling strategy was used to recruit pharmacists for interviews. Community pharmacists known to the research team were contacted via a letter of invitation. 
A senior researcher also circulated letters of invitation within their pharmacist network. A snowballing recruitment strategy was used, where participants were asked to provide contact details of other community pharmacists who might be interested in participating [28]. No more than two pharmacists from the same practice were interviewed.

\section{Participants}

Theme saturation was achieved following 15 interviews. Eleven female and four male pharmacists were recruited with an average of 11 years of experience (range 1-38 years). Participants practiced in 11 different pharmacy practices located across five metropolitan regions of Sydney, New South Wales, Australia. Pharmacists explained that they had frequent contact with people living with gout, and dispensed some form of gout medication at least 2-3 times a week.

\section{Data collection}

Prior to each interview, the purpose of the study was explained to participants and written consent was obtained. Interviews were semi-structured using an interview guide (Table 1). Interview questions focused on the participant's experiences of managing gout, interactions with people living with gout and the perceived role and responsibilities of a pharmacist in gout management. Questions were written with the input from a rheumatologist (RD), a pharmacist (AM) and a qualitative researcher (MB). Oneon-one interviews were conducted in a convenient location for each participant, were $20-30 \mathrm{~min}$ in duration and participants were reimbursed for their time. All interviews were conducted by one researcher, a Medical Science Honours student (AC). Interviews were practiced beforehand to ensure competence in interview delivery and adequate participant understanding of the questions. Interviews were de-identified, audiorecorded and transcribed verbatim. Transcripts were not returned to participants for comment.

\section{Analysis}

Thematic analysis of transcripts was undertaken concurrently with conduct of interviews in order to determine theme saturation. Once theme saturation was achieved no further participants were invited to join the study [29]. Each transcript was analysed independently by two reviewers (AC, AN) using an inductive approach whereby researchers did not analyse transcripts with a pre-determined coding framework. Instead, after analysis of five transcripts, they convened to discuss emerging themes. Emerging themes were categorised into pharmacists' current role and the barriers and facilitators to pharmacist involvement in gout management. A framework was then developed based on the themes that
Table 1 Interview guide

\begin{tabular}{ll}
\hline Theme & Question \\
\hline About the pharmacist & How long have you been practising \\
& pharmacy? How long have you worked \\
& in community pharmacy?
\end{tabular}

About the pharmacist's interaction with people living with gout

Do you often dispense medications used in the treatment and prevention of gout? What are they? What proportion of the scripts would be for allopurinol? What dosages do you typically see on the prescriptions?

What advice do you provide customers about their gout medication and management?

What educational material do you provide customers with gout?

If someone presents to the pharmacy with the symptoms of gout, what do you do? Do you feel you know enough about gout and how it should be managed? What over-the-counter products would you recommend for people with gout?

About the typical person What is your gout customer typically like? with gout in your pharmacy Do they have any co-morbidities?

Are there common complaints and/or challenges that your customers have or encounter with their gout? Does it affect their adherence to prescribed medication or diet?

If you notice that a customer doesn't return for a repeat allopurinol prescription regularly, what advice do you provide? Are there actions that you or your pharmacy takes to help people adhere to their medicines?

Referral to general

practitioner

How often do you refer gout customers to see a doctor and/or get in contact with their GP yourself? What would make you do so?

emerged. This framework was used for analysis of all subsequent transcripts and for reanalysis of the first five transcripts and allowed the most commonly appearing themes to be noted. Discrepancies between reviewers were resolved by consensus.

\section{Results}

Pharmacist responses were grouped into three main areas, being the current role of pharmacists and the facilitators and barriers to their involvement in gout management, and summarised in Table 2 .

\section{Current role of pharmacists in gout management Advice and education}

Pharmacists reported that they provided both pharmacological, diet and lifestyle advice to people with gout. However, only a small number of pharmacists reported that they provided education about the pathogenesis of gout. All pharmacists explained that they provided advice when they first dispensed gout medications but rarely thereafter. One pharmacist said, "To be honest if they've used it before 
Table 2 Summary of pharmacist roles, and facilitators and barriers to involvement, in gout management

\begin{tabular}{lll}
\hline Current roles & Facilitators & Barriers \\
\hline - Provision of advice and education & $\cdot$ Good understanding of gout & $\cdot$ - Difficulty monitoring gout medication adherence \\
- Filling patients' knowledge gaps & and its management & $\cdot$ Lack of pharmacist training for gout \\
- Medication adherence monitoring & & $\cdot$ Gout viewed as less important than other conditions
\end{tabular}

and they've got a history of using [gout medications] regularly I don't generally give them advice" (Pharmacist \#95).

All pharmacists also reported providing some form of written educational material to people with gout, especially if it was the person's first visit to the pharmacy or it was a new medication for the patient. Most commonly, this was the Consumers Medicines Information (CMI) for the medication being dispensed, which is a written plain language summary of Australian Therapeutics Goods Administration approved relevant information available for every prescription medicine in Australia. For example, "First [gout] medication we offer CMI. But for repeat [scripts] we don't offer CMIs anymore” (\#72).

\section{Filling patients' knowledge gaps}

Most pharmacists felt that GPs often did not have time to provide sufficient education to people living with gout in a consultation. Consequently, pharmacists reported that the education they provided filled this gap in gout patients' knowledge. For example, "I think the majority of the time doctors don't [provide enough gout education] and we'll do it for them" (\#97).

\section{Medication adherence monitoring}

Most pharmacists interviewed acknowledged that monitoring patients' adherence to gout medications was not something that was done actively or regularly, however it was recognised as something that should be done. One pharmacist said, "Adherence [to gout medications] is one of those hard things. It's not something that I look at on a general basis" (\#60), while another stated, "it is meant to be a habit when we are dispensing scripts to see how often they're getting their scripts filled... that's a good indication to how compliant someone is" (\#95).

\section{Facilitators to pharmacists' involvement in gout management} Good pharmacist understanding of gout and its management The majority of pharmacists reported having a good understanding of gout medications and their appropriate use. For instance one pharmacist said about allopurinol use, "Don't start taking it if they are still having the gout attack, to wait until the gout settles and then they can start taking their allopurinol" (\#72). A few pharmacists also noted that allopurinol dose "depends on renal function” (\#66). Pharmacists appeared to have sound understanding of the impact of diet and lifestyle on gout, noting "Gout is really related to lifestyle measures and diet” (\#75) and gave appropriate advice regarding diet.

\section{Barriers to pharmacists' involvement in gout management Difficulty monitoring gout medication adherence}

The most common barrier reported by pharmacists was the difficulty in monitoring patient adherence to gout medication. Tracking the intake of gout medications, particularly allopurinol, was said to be difficult from examination of the patient's medication dispensing history because of the sizes of gout medication packs (60 units per pack). This made it hard for pharmacists to detect whether a gout patient was collecting their allopurinol scripts on time. One pharmacist noted, "It's not like a blood pressure tablet where you can see when they come in for their other monthly tablets that they're missing out on their allopurinol. It takes a little bit more detection just to double check that it's been 3 months" (\#66). A potential remedy for this raised by pharmacists was the use of electronic tools such as prompts within the dispensing history software to alert pharmacists. For example, one pharmacist stated, "What makes it easier than ever is...we actually get a prompt if they're not compliant” (\#80).

\section{Lack of specific training in gout and its management}

The majority of pharmacist participants reported a lack of specific professional training or continuing professional education in up to date gout management. For example, one pharmacist stated, "There is no training [in gout]...I get a lot of information by drug reps for every disease under the sun except gout" (\#80). Another reported, "The only training I've done on [gout]...was when the dosing recommendations changed" (\#95). Consequently, a small number of pharmacists stated that they "pretty much rely on...university training" (\#66) or "take it upon myself to do [gout] research" (\#80).

\section{Gout viewed as being less important than other conditions}

Most pharmacist participants reported that gout was a condition that was viewed with lesser importance than other chronic health conditions such as hypercholesterolaemia and cardiovascular disease. For example, a pharmacist said, "We sort of look out more for statins...but not so much the allopurinol...don't think of it as being as important" (\#91). Subsequently, pharmacists felt that gout was not something that was given a lot of focus or high priority. One pharmacist stated, "We may be thinking as we're dispensing that he's got more important conditions to be focusing on at the moment than his gout” (\#95). 


\section{Discussion}

This was the first qualitative study to explore the views of Australian community pharmacists regarding their role in the primary care management of gout. Pharmacists viewed their main role to be providing advice and education to people with gout. Participants demonstrated a good understanding of gout and how it is managed, which could facilitate a greater involvement in the management of people living with gout. The primary barrier to this was their reported difficulty in reliably monitoring adherence to gout medications.

Community pharmacies in Australia are one of the most accessible and convenient points of contact for patients within the healthcare system. This is because due to Australian Government regulations, pharmacies are widely geographically distributed and there is no fee or appointment required for consultations, which can be provided almost immediately [30]. Therefore, although GPs are the primary providers of care and management for people with gout, people visit their community pharmacist more often than their GP. Also contributing to this, is the need to refill repeat prescriptions for gout medications or more commonly, medications for comorbidities strongly associated with gout, such as hypertension [31]. The high accessibility, combined with frequent interactions, provides opportunities for pharmacists to be actively involved and expand their current role in gout management.

Studies have shown that some patients have a poor understanding of gout and its management [14]. This is thought to be due in part to inadequate consumer education provided at the point of diagnosis by their GPs [32]. Pharmacists in this study agreed with this, indicating that they were required to fill the patients' gaps in knowledge about gout and associated medications. Interviews revealed that pharmacists have the knowledge and understanding to inform and educate patients about their gout medications, despite receiving limited training themselves. Patient understanding about medications used in gout management, especially the importance of good adherence, is crucial to optimal gout treatment. It has been suggested that some individuals feel more comfortable speaking with a pharmacist than a GP about their medications [30]. Therefore, an important opportunity exists for pharmacists to provide the muchneeded education to people living with gout.

Despite pharmacists' apparent good understanding of gout, participants reported that they do not always provide education to the patient. Interviews revealed that this was likely to be because of the low priority given to gout management and the limited training and continuing education reportedly received by pharmacists in this area. In Australia, registered community pharmacists have completed university level training and are required to maintain ongoing continuing professional education each year [33]. These findings implicate that it is important that pharmacists are provided with and engage in specific continuing education activities about gout. This would seemingly amplify the importance of gout, and increase the likelihood that pharmacists would provide ongoing patient education (rather than provision of education only at the beginning of treatment as reported in the interviews), which is needed for sustained health improvements [25, 34]. Furthermore, a recent review highlighted the need for more effective and comprehensive educational resources on gout and its management [35]. The development of such resources for use in patientcentred education in the pharmacy may also facilitate pharmacists to provide ongoing education and improve management. Such ongoing medication counselling is also a priority of the Pharmaceutical Society of Australia as outlined in their dispensing practice guidelines [36]. Therefore, it is suggested that pharmacists regularly initiate a conversation with the patient about their understanding of gout and the medication being dispensed at the time of dispensing gout medications.

In order for ULT to be optimally effective, it is imperative that people with gout adhere to medications in the long-term. But, adherence to gout medications is generally very poor [18]. Pharmacists are funded by the Australian Government to provide services such as medication adherence and medication management programs to patients [37]. Interviews revealed that pharmacists viewed monitoring patient adherence to medications as an important part of their role. However, they acknowledged that such monitoring is not routinely done for people taking gout medications. This is likely to contribute to the low medication adherence rates seen in gout. It is important for future practice that pharmacists take the time to check that patients are filling their gout scripts on time and initiate a conversation with the patient about their adherence to their gout medications. Pharmacists did, however, identify a range of factors that made monitoring of adherence to gout medications particularly difficult. This was thought by pharmacists to be primarily due to the large (government subsidised) pack sizes of allopurinol tablets (200 units per pack for $100 \mathrm{mg}$ formulation, 60 units per pack for $300 \mathrm{mg}$ formulation), resulting in lengthy periods between prescription refills. Participants suggested that the availability of electronic systems (e.g. alerts/reminders within the dispensing history software to notify the pharmacist when a patient's script is overdue) would facilitate monitoring adherence. Similar electronic systems have been studied in community pharmacy and have been shown to be effective in preventing inappropriate prescribing and drug interactions and increasing the likelihood of pharmacists undertaking targeted education [38-40]. However, electronic systems to monitor medication adherence are not in widespread use. Thus, the 
development of ways to seamlessly integrate such electronic systems within the day-to-day workings of pharmacies could help pharmacists better monitor adherence. Furthermore, such a system also has the potential to fall within the Australian Government funding agreements with community pharmacies, further incentivising its use [37]. The regular use of electronic systems that provide pharmacists with alerts or reminders about overdue scripts would facilitate them to combat the low medication adherence rates seen in gout and lead to improved clinical outcomes.

\section{Limitations}

In this study, there was reliance on self-reporting, as confirmation of the validity of pharmacist claims through additional studies was not performed. There is also an inherent selection bias when undertaking research that requires recruitment of participants. Individuals who agreed to the study may have been more interested in and/or knowledgeable about gout. However, undertaking continuous recruitment until theme saturation occurs can minimize selection bias. It would also be beneficial to investigate the views of people living with gout about the role of pharmacists, as well as the views of other healthcare providers involved in the management of gout, such as dietitians and GPs.

\section{Conclusions}

This study explored the current role, and barriers and facilitators to involvement of Australian community pharmacists in gout management. Currently, pharmacists report playing a moderate role in assisting patients with managing this condition, mainly providing advice and education. Pharmacists' good understanding of gout was seen to facilitate their involvement in gout management, but their lack of training and consideration for gout, together with difficulties in monitoring adherence to gout medications, prevented further involvement in its management. In this study, areas of opportunity to expand pharmacists' role in gout management were also identified with the potential to lead to significant improvements in gout management in the community. These future implications for pharmacist practice include providing targeted ongoing education to people living with gout each time gout medications are dispensed, actively undertaking continuing education in gout, initiating conversations at the point of dispensing with the patient about their medication adherence, actively checking gout medication dispensing history and integrating electronic systems into pharmacies to assist with monitoring medication adherence.

\section{Abbreviations}

CMI: Consumers medicines information; GP: General practitioner; UA: Uric acid; ULT: Urate-lowering therapy

\section{Acknowledgements}

The help and guidance of Associate Professor Parisa Aslani in the review of the interview guide and recruitment of pharmacists is greatly acknowledged.

\section{Funding}

Funding was provided by the Lexy Davies Bequest at St Vincent's Hospital, Sydney. The funding body had no input in the design of the study, or collection, analysis, and interpretation of data and writing of the manuscript.

\section{Availability of data and materials}

The datasets generated and/or analysed during the current study are not publicly available due to the need for individual participant privacy but are available from the corresponding author on reasonable request.

\section{Authors' contributions}

AC contributed to the development of the interview guide, organised recruitment of participants, performed interviews with participants, transcribed interviews, co-analysed and interpreted interview data, and was a major contributor in writing of the manuscript. AN contributed to the conception and design of the study and development of the interview guide, co-analysed and interpreted interview data, and was a major contributor in critically revising the manuscript. MB contributed to the conception and design of the study and development of the interview guide, provided guidance and support in the use of qualitative methods, and was a major contributor in critically revising the manuscript. DK contributed to the conception and design of the study, provided guidance on gout related matters, and contributed in critically revising the manuscript. AM was a major contributor in the development of the interview guide, assisted with recruitment of participants, provided guidance on pharmacist related matters, and contributed in critically revising the manuscript. RD contributed to the conception and design of the study and development of the interview guide, supervised the research group and the overall study, provided guidance on gout related matters, and contributed in critically revising the manuscript. All authors read and approved the final manuscript.

Ethics approval and consent to participate

Ethics approval for the study was obtained from The University of New South Wales Human Research Ethics Advisory Panel (reference \#2014-7-10). Informed consent to participate in the study was obtained in writing from each participant prior to commencement of interviews.

\section{Competing interests}

The authors declare that they have no competing interests.

\section{Publisher's Note}

Springer Nature remains neutral with regard to jurisdictional claims in published maps and institutional affiliations.

\section{Author details}

'Department of Clinical Pharmacology \& Toxicology, St Vincent's Hospital, Sydney, NSW, Australia. ${ }^{2}$ School of Medical Sciences, University of New South Wales, Sydney, NSW, Australia. ${ }^{3}$ St Vincent's Clinical School, St Vincent's Hospital, University of New South Wales, Sydney, NSW, Australia. ${ }^{4}$ Centre for Health Systems and Safety Research, Australian Institute of Health Innovation, Macquarie University, Sydney, NSW, Australia. ${ }^{5}$ Faculty of Pharmacy, University of Sydney, Sydney, NSW, Australia. ${ }^{6}$ Centre for Education and Research on Ageing, Concord Repatriation General Hospital, Sydney, NSW, Australia.

Received: 7 November 2017 Accepted: 23 April 2018

Published online: 09 May 2018

\section{References}

1. Roddy E, Mallen CD, Doherty M. Gout. BMJ. 2013;347:f5648

2. Smith HS, Bracken D, Smith JM. Gout: current insights and future perspectives. J Pain. 2011:12(11):1113-29.

3. Zhu Y, Pandya BJ, Choi HK. Prevalence of gout and hyperuricemia in the US general population: the National Health and nutrition examination survey 2007-2008. Arthritis Rheum. 2011;63(10):3136-41. 
4. Kuo C-F, Grainge MJ, Zhang W, Doherty M. Global epidemiology of gout: prevalence, incidence and risk factors. Nat Rev Rheumatol. 2015;11(11):649-62.

5. Kuo CF, Grainge MJ, Mallen C, Zhang W, Doherty M. Rising burden of gout in the UK but continuing suboptimal management: a nationwide population study. Ann Rheum Dis. 2015;74(4):661-7.

6. Robinson $P$, Taylor W, Merriman T. Systematic review of the prevalence of gout and hyperuricaemia in Australia. Intern Med J. 2012:42(9):997-1007.

7. Robinson PC, Taylor WJ, Dalbeth N. An observational study of gout prevalence and quality of care in a national Australian general practice population. J Rheumatol. 2015;42(9):1702-7.

8. Jordan KM, Cameron JS, Snaith M, Zhang W, Doherty M, Seckl J, et al. British Society for Rheumatology and British health professionals in rheumatology guideline for the management of gout. Rheumatology (Oxford). 2007;46(8):1372-4.

9. Khanna D, Fitzgerald JD, Khanna PP, Bae S, Singh MK, Neogi T, et al. 2012 American College of Rheumatology guidelines for management of gout. Part 1: systematic nonpharmacologic and pharmacologic therapeutic approaches to hyperuricemia. Arthritis Care Res. 2012;64(10):1431-46.

10. Khanna D, Khanna PP, Fitzgerald JD, Singh MK, Bae S, Neogi T, et al. 2012 American College of Rheumatology guidelines for management of gout. Part 2: therapy and antiinflammatory prophylaxis of acute gouty arthritis. Arthritis Care Res. 2012;64(10):1447-61.

11. Graf SW, Whittle SL, Wechalekar MD, Moi JH, Barrett C, Hill CL, et al. Australian and New Zealand recommendations for the diagnosis and management of gout: integrating systematic literature review and expert opinion in the 3e initiative. Int J Rheum Dis. 2015;18(3):341-51.

12. Richette P, Doherty M, Pascual E, Barskova V, Becce F, Castañeda-Sanabria J, et al. 2016 updated EULAR evidence-based recommendations for the management of gout. Ann Rheum Dis. 2017;76:29-42.

13. Harrold LR, Mazor KM, Negron A, Ogarek J, Firneno C, Yood RA. Primary care providers' knowledge, beliefs and treatment practices for gout: results of a physician questionnaire. Rheumatology (Oxford). 2013;52(9):1623-9.

14. Vaccher S, Kannangara DRW, Baysari MT, Reath J, Zwar N, Williams KM, et al. Barriers to care in gout: from prescriber to patient. J Rheumatol. 2016;43(1):144-9.

15. Cottrell E, Crabtree V, Edwards JJ, Roddy E. Improvement in the management of gout is vital and overdue: an audit from a UK primary care medical practice. BMC Fam Pract. 2013:14(1):170.

16. Harrold LR, Andrade SE, Briesacher BA, Raebel MA, Fouayzi H, Yood RA, et al. Adherence with urate-lowering therapies for the treatment of gout. Arthritis Res Ther. 2009;11(2):R46.

17. Briesacher BA, Andrade SE, Fouayzi H, Chan KA. Comparison of drug adherence rates among patients with seven different medical conditions. Pharmacotherapy. 2008;28(4):437-43.

18. McGowan B, Bennett K, Silke C, Whelan B. Adherence and persistence to uratelowering therapies in the Irish setting. Clin Rheumatol. 2016;35(3):715-21.

19. Spencer K, Carr A, Doherty M. Patient and provider barriers to effective management of gout in general practice: a qualitative study. Ann Rheum Dis. 2012:71(9):1490-5.

20. Rees F, Jenkins W, Doherty M. Patients with gout adhere to curative treatment if informed appropriately: proof-of-concept observational study. Ann Rheum Dis. 2013;72(6):826-30.

21. Benrimoj SI, Roberts AS. Providing patient care in community pharmacies in Australia. Ann Pharmacother. 2005;39(11):1911-7.

22. The Pharmacy Guild of Australia. Community pharmacy. 2014. https://www. guild.org.au/_data/assets/pdf_file/0010/6121/pgoa-submission-to-thecompetition-policy-review-june-2014_573492_3.pdf. Accessed 1 Oct 2017.

23. Van C, Mitchell B, Krass I. General practitioner-pharmacist interactions in professional pharmacy services. J Interprof Care. 2011;25(5):366-72.

24. Elliott RA, Boyd MJ, Salema N-E, Davies J, Barber N, Mehta RL, et al. Supporting adherence for people starting a new medication for a longterm condition through community pharmacies: a pragmatic randomised controlled trial of the new medicine service. BMJ Qual Saf. 2015; https://doi.org/10.1136/bmjas-2015-004400

25. Mehuys E, Van Bortel L, De Bolle L, Van Tongelen I, Annemans L, Remon JP, et al. Effectiveness of a community pharmacist intervention in diabetes care: a randomized controlled trial. J Clin Pharm Ther. 2011;36(5):602-13.

26. Lyons I, Barber N, Raynor DK, Wei L. The medicines advice service evaluation (MASE): a randomised controlled trial of a pharmacist-led telephone based intervention designed to improve medication adherence. BMJ Qual Saf. 2016;25(10):759-69.
27. Goldfien R, Pressman A, Jacobson A, Ng M, Avins A. A pharmacist-staffed, virtual gout management clinic for achieving target serum uric acid levels: a randomized clinical trial. Perm J. 2016;20(3):18-23.

28. Noy C. Sampling knowledge: the hermeneutics of snowball sampling in qualitative research. Int J Soc Res Methodol. 2008;11(4):327-44.

29. Marshall MN. Sampling for qualitative research. Fam Pract. 1996;13(6):522-6.

30. McMillan SS, Wheeler AJ, Sav A, King MA, Whitty JA, Kendall E, et al. Community pharmacy in Australia: a health hub destination of the future. Res Social Adm Pharm. 2013;9(6):863-75.

31. Zhu Y, Pandya BJ, Choi HK. Comorbidities of gout and hyperuricemia in the US general population: NHANES 2007-2008. Am J Med. 2012;125(7):679-87. e1

32. Chandratre P, Mallen CD, Roddy E, Liddle J, Richardson J. "You want to get on with the rest of your life": a qualitative study of health-related quality of life in gout. Clin Rheumatol. 2016;35(5):1197-205.

33. Moles RJ, Stehlik P. Pharmacy practice in Australia. Can J Hosp Pharm. 2015; 68(5):418-26

34. Eussen SR, MEvd E, Klungel OH, Rompelberg CJ, Garssen J, Oosterveld $\mathrm{MH}$, et al. A pharmaceutical care program to improve adherence to statin therapy: a randomized controlled trial. Ann Pharmacother. 2010; 44(12):1905-13.

35. Johnston ME, Treharne GJ, Chapman PT, Stamp LK. Patient information about gout: an international review of existing educational resources. J Rheumatol. 2015;42(6):975-8.

36. Pharmaceutical Society of Australia. Dispensing practice guidelines. 2017. http://www.psa.org.au/wp-content/uploads/Dispensing-Practice-Guidelines2017-pdf-8.3MB.pdf. Accessed 15 Feb 2018.

37. The Department of Health. Sixth Community Pharmacy Agreement. 2015. http://www.pbs.gov.au/general/pbs-access-sustainability/signed-sixthcommunity-pharmacy-agreement-commonwealth-and-pharmacy-guild.pdf. Accessed 1 Oct 2017.

38. Raebel MA, Charles J, Dugan J, Carroll NM, Korner EJ, Brand DW, et al. Randomized trial to improve prescribing safety in ambulatory elderly patients. J Am Geriatr Soc. 2007:55(7):977-85.

39. Curtain C, Peterson G. Review of computerized clinical decision support in community pharmacy. J Clin Pharm Ther. 2014;39(4):343-8.

40. Reeve JF, Tenni PC, Peterson GM. An electronic prompt in dispensing software to promote clinical interventions by community pharmacists: a randomized controlled trial. Br J Clin Pharmacol. 2008;65(3):377-85.

\section{Ready to submit your research? Choose BMC and benefit from:}

- fast, convenient online submission

- thorough peer review by experienced researchers in your field

- rapid publication on acceptance

- support for research data, including large and complex data types

- gold Open Access which fosters wider collaboration and increased citations

- maximum visibility for your research: over $100 \mathrm{M}$ website views per year

At BMC, research is always in progress.

Learn more biomedcentral.com/submissions 